\title{
ALK 1 Negative Inflammatory Myofibroblastic Tumor of the lleum: A Rare Cause of Ileocecal Intussusception
}

\author{
Vipul D. Yagnik, MS, FMAS, FIAGES, FAIS, FISCP1 ${ }^{10}$ \\ ${ }^{1}$ Department of Surgical Gastroenterology, Nishtha Surgical Hospital \\ and Research Centre, Patan, Gujarat, India \\ Address for correspondence Vipul D. Yagnik, MS, FMAS, FIAGES, FAIS, \\ FISCP, 77, Siddhraj Nagar, Rajmahal Road, Patan 384265, Gujarat, \\ India (e-mail: vipul.yagnik@gmail.com).
} Surg J 2020;6:e101-e104.
Abstract
Keywords
- inflammatory
myofibroblastic
tumor
- small bowel
- intussusception

An inflammatory myofibroblastic tumor is a rare tumor of mesenchymal background commonly found in the pulmonary system. It is rarely found as a primary tumor in the gastrointestinal tract. We report an unusual presentation of this rare lesion causing intussusception and intestinal obstruction in a 39-year-old male.
Inflammatory myofibroblastic tumor (IMT) belongs to a class of rare spindle cell tumors and was previously called inflammatory pseudotumor or plasma cell granuloma. The World Health Organization classifies IMTs as tumors of intermediate biological potential since both local recurrence and metastases are possible. ${ }^{1,2}$ IMT affects children and young adults predominantly, but patients of any age and sex can be affected. ${ }^{3}$ Gastrointestinal tract (GIT) IMT presents with clinical symptoms of anemia, loss of appetite or weight, fecal blood positive, abdominal pain, GIT obstruction, or intussusception. IMT is generally expected to have a benign course. However, extrapulmonary origin, size $>8 \mathrm{~cm}$, and local invasion are the factors associated with an elevated risk of recurrence which mostly occurs within 2 years of the initial surgery.

\section{Case History}

A 39-year-old male presented to the surgical outpatient department with complaints of abdominal distension and pain for 3 to 4 days. He also reported vomiting and obstipation for the same duration. His past medical and surgical history was not significant. Physical examination revealed abdominal distension with tenderness in the right lower quadrant. Bowel sounds were hyperperistaltic. Laboratory investigations were normal. Abdominal ultrasound revealed bowel-within-bowel appearance in the right lower quadrant,

received

November 12, 2019

accepted

March 12, 2020 the segment being approximately $8-\mathrm{cm}$ long with a lead point of approximately $50 \times 29 \times 28 \mathrm{~mm}$ in the cecum.

We performed colonoscopy and planned colonoscopic reduction and removal of the lead point. A lead point was seen projecting through the ileocecal valve ( - Fig. 1). Though colonoscopic reduction was achieved, the lead point was beyond the limit of the standard length of the colonoscope. Therefore, we performed laparotomy via a midline incision. The lead point was palpated $25 \mathrm{~cm}$ proximal to the ileocecal junction. Segmental resection of the terminal ileum was performed. The resected segment revealed a polypoidal lesion (-Fig. 2). Histopathology of the specimen was consistent with a spindle cell tumor (-Fig. 3). Immunohistochemistry was positive for smooth muscle actin (-Fig. 4) and vimentin (-Fig. 5), but negative for CD117, DOG1, Desmin, CD34, S100, and ALK 1. Overall, the immunomorphological profile excluded gastrointestinal (GI) stromal tumors and suggested the diagnosis of IMT. The postoperative course was unremarkable and the patient was discharged on the fifth postoperative day. The patient has been followed up for 2 years without any problem.

\section{Discussion}

An IMT is a rare tumor of mesenchymal background commonly found in the pulmonary system. Dr. H. Brunn first described IMTs in 1939. ${ }^{4}$ It is also known as a pseudotumor
Copyright $\odot 2020$ by Thieme Medical Publishers, Inc., 333 Seventh Avenue, New York, NY 10001, USA. Tel: +1(212) 760-0888.
License terms

10.1055/s-0040-1710531. ISSN 2378-5128.

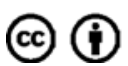




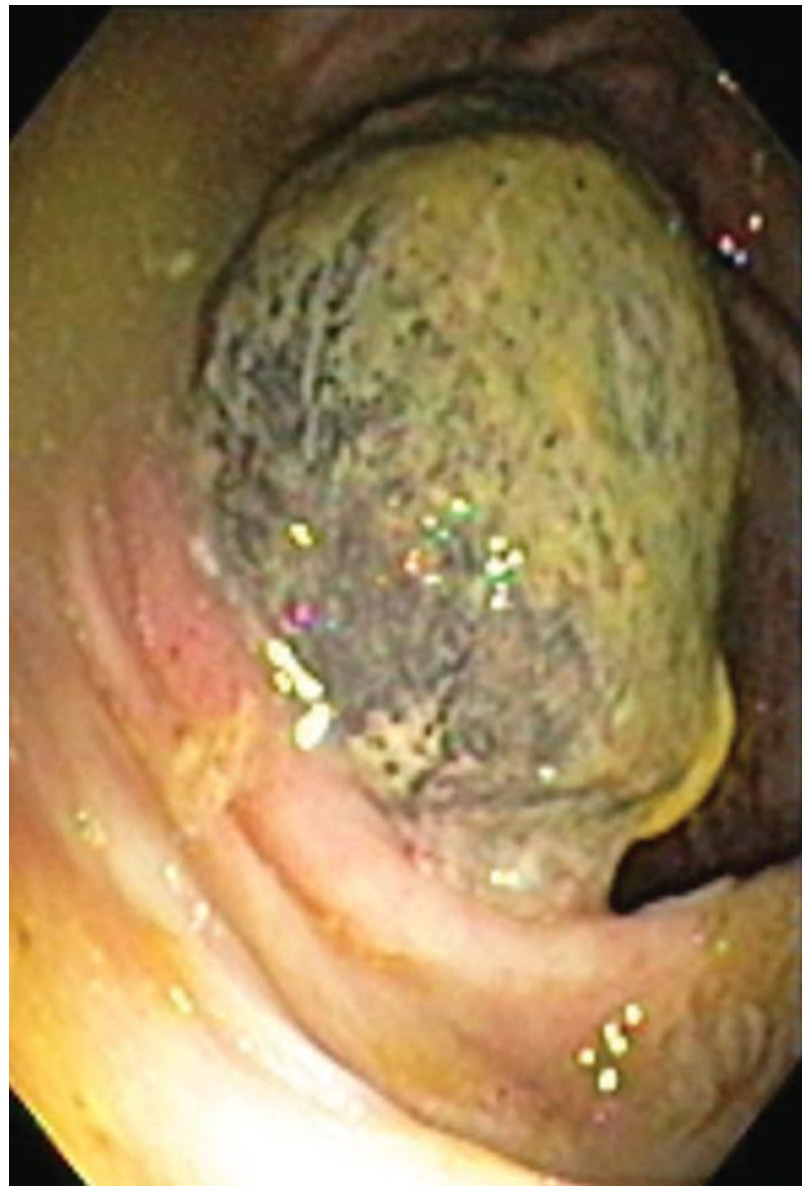

Fig. 1 Colonoscopic image showing lead point projecting through ileocecal valve.

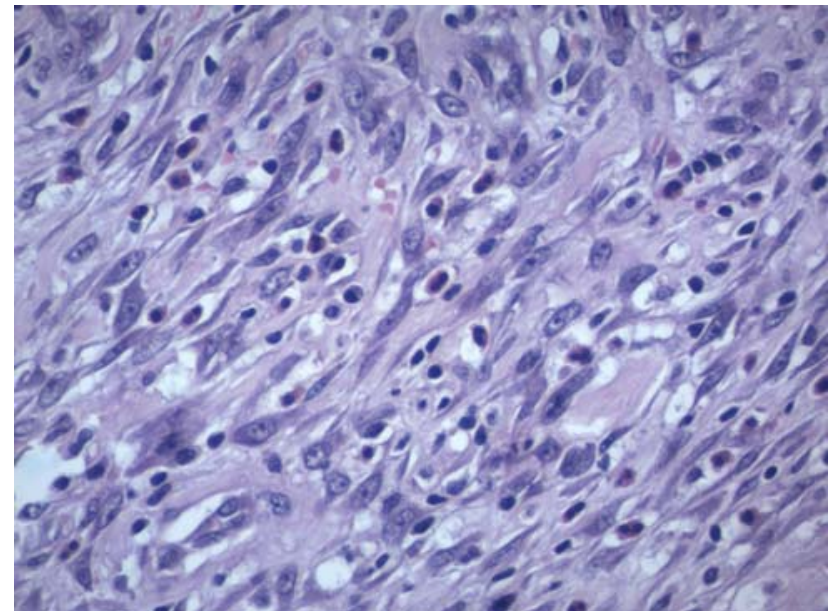

Fig. 3 40X H\&E stain: IMT composed of spindle cells along with mixed inflammatory infiltrate. $\mathrm{H} \& \mathrm{E}$ stain, hematoxylin and eosin stain; IMT, Inflammatory myofibroblastic tumor.

with malignant potential. ${ }^{5}$ The World Health Organization classifies IMT as tumors of intermediate biological potential since both local recurrence and metastases are possible., ${ }^{1,2}$ Coffin et $\mathrm{al}^{3}$ showed that IMT developed at a mean age of 9.7 years, and in 36 of 84 cases (43\%), IMTs arose from the mesentery and omentum. Höhne et $\mathrm{al}^{6}$ reviewed 443 publications from between 2009 to February 2014; their reports involved 938 patients and 956 organ sites. They found liver involvement in $31.8 \%$ of the cases followed by lung involvement in $18.2 \%$ cases. Abdominal association excluding the liver was noted in $15.5 \%$ of the cases. Out of 956 organ sites affected, involvement of the small bowel was reported in only 11 locations (1.15\%). ${ }^{6}$ GIT IMT presents with clinical symptoms of anemia, loss of appetite or weight, fecal blood

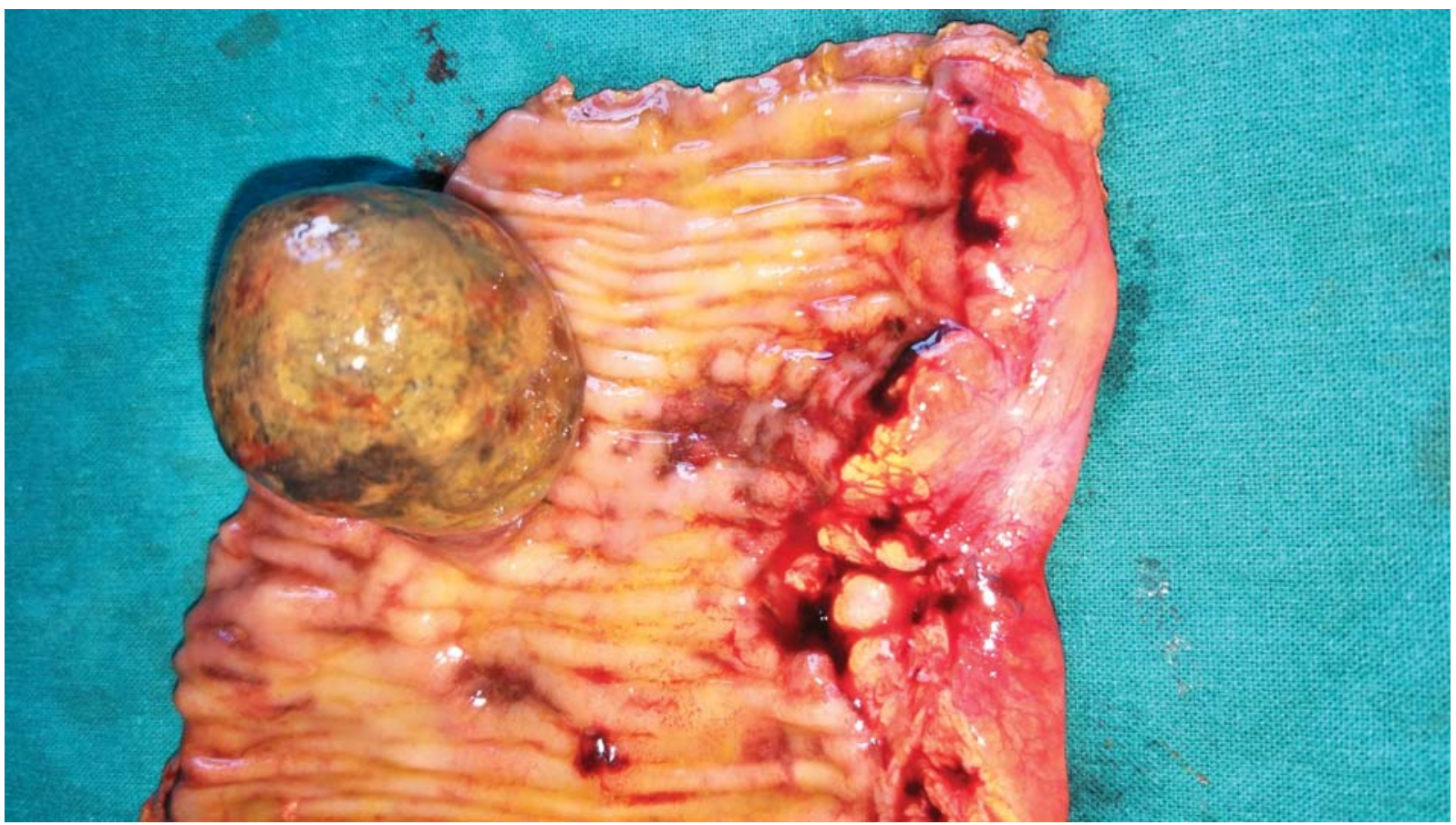

Fig. 2 Resected segment of the small bowel showed polypoidal lesion. 


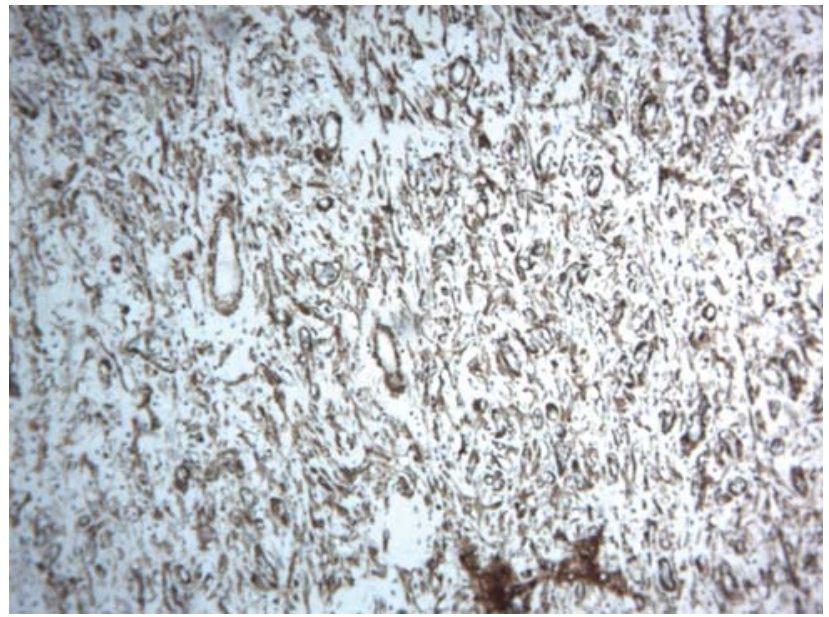

Fig. 4 IHC 10X: IMT composed of spindle cells with SMA positive. IHC, immunohistochemistry; IMT, Inflammatory myofibroblastic tumor.

positive, ${ }^{7}$ abdominal pain, GI obstruction, ${ }^{8}$ or intussusception. $^{9}$ Immunohistochemistry helps to differentiate IMT from other spindle cell tumor-like GI stromal tumors, leiomyosarcomas, and inflammatory malignant fibrous histiocytomas. ${ }^{10}$ Surgical excision is considered the treatment of choice for a GIT IMT, although anti-inflammatory drugs and/or chemoradiotherapy have been used. ${ }^{11,12}$ Approximately $50 \%$ of the IMTs have a clonal rearrangement of the ALK gene and this can also be used as a specific marker to differentiate other tumors. However, ALK negativity is not a criterion to exclude IMT. ALK positivity is seen more in younger individuals and is associated with a higher recurrence rate. ${ }^{11}$ Extrapulmonary origin, size $>8 \mathrm{~cm}$, and local invasion are the factors associated with an elevated risk of recurrence. ${ }^{13}$ Postsurgical adjuvant treatments might be considered in abdominal IMT as it has the highest rate of local recurrence (25\%). ${ }^{14}$ Long-term follow-up is advisable in the patient treated with surgery to investigate the risk of recurrence. $^{15,16}$

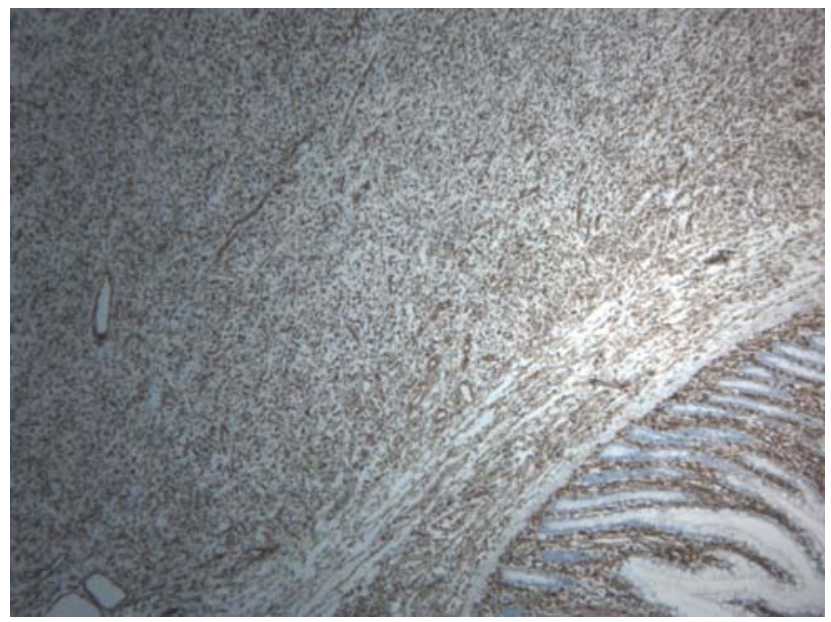

Fig. 5 IHC 10X: IMT composed of spindle cells with Vimentin positive. IHC, immunohistochemistry; IMT, Inflammatory myofibroblastic tumor.

\section{Conclusion}

Intussusception due to IMT is rare. Diagnosis of IMT involving the GIT requires a high index of suspicion, detailed history, physical examination, and imaging studies that are necessary for early recognition and diagnosis. Surgery is the cornerstone of treatment. Long-term follow-up is required to detect recurrence.

\section{Funding}

No financial support. The manuscript has not been published and is not under consideration for publication elsewhere. The manuscript is approved by all the authors.

\section{Conflict of Interest}

None.

\section{Acknowledgment}

I would like to acknowledge the help provided by Dr. Sushil Dawka, professor of surgery, SSR Medical College, Mauritius in editing of the manuscript.

\section{References}

1 Fong SS, Zhao C, Yap WM, Loke SC, Lim KH. Inflammatory myofibroblastic tumour of the duodenum. Singapore Med J 2012;53(02):e28-e31

2 Unver N, Coban G, Onaran OI, Kunduz E, Arslan A, Malya FU, et al. Co-existence of acute appendicitis and inflammatory myofibroblastic tumor of the small intestine: a case report. Annal Med Surg 2015;4(03):217-220

3 Coffin CM, Watterson J, Priest JR, Dehner LP. Extrapulmonary inflammatory myofibroblastic tumor (inflammatory pseudotumor). A clinicopathologic and immunohistochemical study of 84 cases. Am J Surg Pathol 1995;19(08):859-872

4 Brunn $\mathrm{H}$. Two interesting benign lung tumors of contradictory histopathology. J Thorac Surg 1939;9:119-131

5 Sternberg SS, Mills SE, Carter D. Sternberg's Diagnostic Surgical Pathology. Philadelphia, PA: Lippincott Williams \& Wilkins; 2004

6 Höhne S, Milzsch M, Adams J, Kunze C, Finke R. Inflammatory pseudotumor (IPT) and inflammatory myofibroblastic tumor (IMT): a representative literature review occasioned by a rare IMT of the transverse colon in a 9-year-old child. Tumori 2015;101 (03):249-256

7 Gurzu S, Bara T, Jung I. Inflammatory myofibroblastic tumor of the colon. J Clin Oncol 2013;31(10):e155-e158

8 Petrovic I, Augustin G, Hlupic L, Nedic A, Romic I, Skegro M. Inflammatory myofibroblastic tumors of the duodenum. Asian J Surg 2016;39(04):247-252

9 Milne ANA, Sweeney KJ, O'Riordain DS, et al. Inflammatory myofibroblastic tumor with ALK/TPM3 fusion presenting as ileocolic intussusception: an unusual presentation of an unusual neoplasm. Hum Pathol 2006;37(01):112-116

10 Nagae I, Hamasaki Y, Tsuchida A, et al. Primary omental-mesenteric myxoid hamartoma of the mesoappendix incidentally detected after abdominal trauma in a child: report of a case. Surg Today 2005;35(09):792-795

11 Kim EY, Lee IK, Lee YSet al. Inflammatory myofibroblastic tumor in colon. J Korean Surg Soc 2012;82(01):45-49

12 Karnak I, Senocak ME, Ciftci AO, et al. Inflammatory myofibroblastic tumor in children: diagnosis and treatment. J Pediatr Surg 2001;36(06):908-912 
e104 ALK 1 Negative Inflammatory Myofibroblastic Tumor of the Ileum Yagnik

13 Ladd AP, Grosfeld JL. Gastrointestinal tumors in children. In: Carachi R, Grosfeld JL, eds. The Surgery of Childhood Tumors. Berlin: Springer; 2016:257-268

14 Fletcher CDM, Bridge JA, Hogendoorn P, Mertens F. WHO Classification of Tumours of Soft Tissue and Bone. 4th ed. Lyon: IARC Press; 2013
15 Coffin CM, Hornick JL, Fletcher CD. Inflammatory myofibroblastic tumor: comparison of clinicopathologic, histologic, and immunohistochemical features including ALK expression in atypical and aggressive cases. Am J Surg Pathol 2007;31(04):509-520

16 Yagnik VD. Re: inflammatory myofibroblastic tumour of sigmoid mesocolon in a child. ANZ J Surg 2019;89(1-2):133-134 